\title{
ASSOCIATION OF SERUM PROLACTIN WITH INFERTILITY
}

\author{
Lakshmi $G^{1}$, Sheela Balakrishnan², Syamsundar O. $S^{3}$ \\ ${ }_{1}^{1}$ Associate Professor, Department of Physiology, Government Medical College, Trivandrum. \\ 2 Professor, Department of Obstetrics and Gynaecology, Government Medical College, Trivandrum. \\ 3Physician, General Hospital, Trivandrum.
}

\section{ABSTRACT}

\section{BACKGROUND}

Hyperprolactinaemia was found to be an important cause of infertility in early seventies. Despite adequate release of gonadotropic hormones, in the presence of hyperprolactinaemia, ovulation fails to occur. Suppression of prolactin concentration to normal led to resumption of normal menstrual pattern.

The aim of this study was to find out the association between serum prolactin and infertility in females of reproductive age group.

\section{MATERIALS AND METHODS}

In this prospective study, fifty females of reproductive age group with irregular periods were selected as cases; control group comprised fifty females of reproductive age group with regular periods. The parameters studied were body mass index, recent weight gain, dysmenorrhoea, dyspareunia, hirsutism, galactorrhoea and serum prolactin. Estimation of serum prolactin was done using Coat-A-Count prolactin IRMA, an immunoradiometric assay designed for the quantitative measurement of prolactin in serum. Statistical analysis done using Pearson Chi square test.

Settings and Design- Prospective longitudinal study.

\section{RESULTS}

Cases with BMI greater than 25 were 38\%, recent weight gain 42\%, hirsutism 38\%, dysmenorrhoea $84 \%$, dyspareunia $24 \%$, galactorrhoea $12 \% .22 \%$ cases show higher prolactin levels, out of these $12 \%$ only presented with galactorrhoea.

\section{CONCLUSION}

Serum prolactin has a definite role in infertility.

\section{KEYWORDS}

Pregnancy, Serum Prolactin, Infertility, Galactorrhoea, Dysmenorrhoea, Dyspareunia.

HOW TO CITE THIS ARTICLE: Lakshmi G, Balakrishnan S, Syamsundar OS. Association of serum prolactin with infertility.J.EvolutionMed.Dent.Sci.2017;6(25):2061-2064, DOI:10.14260/Jemds/2017/448

\section{BACKGROUND}

In any community, mothers and children constitute a priority group in India, women of the child bearing age (15-44 years) constitute $19 \%$. With the advent of modern techniques and treatment strategies, we have now revealed many a cause of infertility and this information is leading us to quite unknown fields where the treasures lay in the depth to be explored. Though the problem of infertility remained quite ignored, it definitely imparts a social stigma and a constant mental agony to the couple concerned.

There are many factors that may cause increasing infertility. Even under ideal conditions, the probability that a woman will get pregnant during a single menstrual cycle is only $30 \%$, but even when conception does occur, only 50 $60 \%$ pregnancy advances beyond $20^{\text {th }}$ week. Among the female causes of infertility, $59 \%$ is contributed by ovarian dysfunction. ${ }^{1}$

Financial or Other, Competing Interest: None.

Submission 07-03-2017, Peer Review 19-03-2017,

Acceptance 22-03-2017, Published 27-03-2017.

Corresponding Author:

Dr. Lakshmi G,

Associate Professor,

Department of Physiology,

Government Medical College,

Trivandrum.

E-mail:lakshmi.syam92@gmail.com

DOI:10.14260/jemds $/ 2017 / 448$

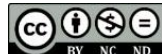

Hyperprolactinaemia was found to be an important cause of infertility in early seventies. Early changes of serum prolactin level could lead to subtle changes in ovulation which might have profound effects on infertility, but abnormal levels of serum prolactin relate largely to changes in ovulation. Changes in serum prolactin level produce menstrual irregularities and problems related to reproductive function is not a new development.

There is a direct impact of serum prolactin level on luteal function of the ovary. High concentrations of prolactin was associated with normal or low blood concentration of luteinising hormone or follicle stimulating hormone and adequate release In response to gonadotropic releasing hormone (Thorner et al, 1974). High concentration of prolactin while closely associated with ovarian activity might not act directly on the ovary and maintenance of ovarian function by exogenous gonadotropins might overcome any direct inhibitory effect of prolactin on gonads. In vitro, high concentration of prolactin equivalent to those seen in lactation, inhibit progesterone production by human granulosa cells even in the presence of high FSH and LH. (McNatty et al 1974). ${ }^{2}$ In the presence of high prolactin levels, blood concentrations of FSH are high normal and of LH low normal without pulsatile secretion and there is absence of ovarian activity as judged by an absence of oestrogen secretion. Despite adequate release of FSH and $\mathrm{LH}^{3}$ in the pituitary, oestrogen fails to induce a positive feedback release of LH and hypothalamus-pituitary axis appear more sensitive 
to the negative feedback effect of oestrogen. Suppression of prolactin concentration to normal led to the resumption of normal menstrual cycle. (Rolland et al 1975. Glass et al 1975). .45 Hence the study was undertaken with the hope that incidence of infertility may be reduced by proper monitoring of the serum prolactin level. Any defect of the prolactin level may be treated so that we will be more confident in reducing the chance of infertility through this approach.

How serum prolactin levels affect the fertility of a woman? This is a question to be answered in the present scenario. Infertility is a complex medical, social and individual problem but nothing is known about the risk factors and their mechanism of action in the study of reduced fertility. This was what inspired us to probe into this topic.

\section{MATERIALS AND METHODS}

Fifty female patients of reproductive age group with irregular periods attending the infertility clinic in SAT Hospital, Thiruvananthapuram were selected as the study group. The control group comprised of fifty patients selected from females of reproductive age group with regular periods. Among the cases were females of reproductive age group not conceiving after one year of unrestricted intercourse with no abnormality detected in their partners and females having infertility with irregular periods. Those with generalised illness, endocrine disorders, congenital abnormalities of female genital tract were excluded from the study. Parameters studied were body mass index, recent weight gain, dysmenorrhoea, dyspareunia, hirsutism, galactorrhoea and serum prolactin. Estimation of serum prolactin was done using Coat-A-Count prolactin IRMA, an immunoradiometric assay designed for the quantitative measurement of prolactin in serum.

\section{Statistical Analysis}

For the entry of the statistical data, the computer package used was Microsoft excel. For analysis, SPSS of windows Version 10 was used. $P$ value of $<0.01$ was considered highly significant, $\mathrm{P}$ value of $<0.05$ was considered significant, $\mathrm{P}$ value of $>0.05$ was not considered to be significant statistically. Association among variables was assessed using Pearson chi square test.

\section{RESULTS}

$38 \%$ among the case group shows values of body mass index greater than 25 whereas only $12 \%$ among the control group shows values greater than $25.80 \%$ of the control group and $50 \%$ of the case group had body mass index within the normal range (Table 1). $42 \%$ of the cases show recent weight gain whereas none among controls show recent weight gain. (Table 2). Hirsutism is present in $38 \%$ of cases whereas none among the controls show hirsutism.

$84 \%$ of the patients among the case group presented with dysmenorrhoea whereas only 18 among the control group presented with the same symptom. $82 \%$ among the control group showed no symptom of dysmenorrhoea, so the association of dysmenorrhoea and infertility was found to be statistically very highly significant. (Table 3 ). $24 \%$ among the cases presented with dyspareunia whereas none among the control group presented with dyspareunia. (Figure 1).

$12 \%$ among the cases presented with galactorrhoea and $88 \%$ among the cases did not present with galactorrhoea. Since none among the control group presented with galactorrhoea, the association of galactorrhoea and infertility was found to be statistically highly significant. (Table 4).

$78 \%$ among the cases showed normal prolactin levels whereas $22 \%$ were with prolactin levels greater than $25 \mathrm{ng} / \mathrm{mL}$. Out of these $22 \%$, only $12 \%$ cases presented with galactorrhoea. So, all patients with raised prolactin levels need not present with galactorrhoea. None among the controls showed raised prolactin levels. (Figure 1).

\begin{tabular}{|c|c|c|}
\hline BMI & \multicolumn{2}{|c|}{ Group } \\
\cline { 2 - 3 }$\left(\mathbf{K g} / \mathbf{m}^{2}\right)$ & Cases & Control \\
\hline \multirow{2}{*}{$<18$} & 6 & 4 \\
& $12.0 \%$ & $8.0 \%$ \\
\hline \multirow{2}{*}{$18-25$} & 25 & 40 \\
& $50.0 \%$ & $80.0 \%$ \\
\hline \multirow{2}{*}{$>25$} & 19 & 6 \\
& $38.0 \%$ & $12.0 \%$ \\
\hline \multicolumn{3}{|c|}{ Table 1. BMI } \\
\hline
\end{tabular}

Chi square test Value P. Value Highly Significant.

With Yates correction 10.622, 0.005.

\begin{tabular}{|c|c|c|}
\hline \multirow{2}{*}{ Dysmenorrhoea } & \multicolumn{2}{|c|}{ Group } \\
\cline { 2 - 3 } & Cases & Control \\
\hline \multirow{2}{*}{ No } & 8 & 41 \\
& $16.0 \%$ & $82.0 \%$ \\
\hline \multirow{2}{*}{ Yes } & 42 & 9 \\
& $84.0 \%$ & $18.0 \%$ \\
\hline \multicolumn{2}{|c|}{ Table 2. Dysmenorrhoea } \\
\hline
\end{tabular}

Chi square test Value P. Value Very Highly Significant. With Yates correction 43.577, 0.000.

\begin{tabular}{|c|c|c|}
\hline \multirow{2}{*}{ Dyspareunia } & \multicolumn{2}{|c|}{ Group } \\
\cline { 2 - 3 } & Cases & Control \\
\hline \multirow{2}{*}{ No } & 38 & 50 \\
& $76.0 \%$ & $100.0 \%$ \\
\hline \multirow{2}{*}{ Yes } & 12 & 0 \\
& $24.0 \%$ & 0 \\
\hline \multicolumn{2}{|c|}{ Table 3. Dyspareunia } \\
\hline
\end{tabular}

Chi square test Value P. Value Very Highly Significant. With Yates correction 13.636, 0.000 .

\begin{tabular}{|c|c|c|}
\hline \multirow{2}{*}{ Hirsutism } & \multicolumn{2}{|c|}{ Group } \\
\cline { 2 - 3 } & Cases & Control \\
\hline \multirow{2}{*}{ No } & 30 & 50 \\
& $60.0 \%$ & $100.0 \%$ \\
\hline \multirow{2}{*}{ Yes } & 19 & 0 \\
& $38.0 \%$ & 0 \\
\hline \multicolumn{3}{|c|}{ Table 4. Hirsutism } \\
\hline
\end{tabular}

Chi square test Value P. Value Very Highly Significant With Yates correction 25.0, 0.000

\begin{tabular}{|c|c|c|}
\hline \multirow{2}{*}{ Prolactin } & \multicolumn{2}{|c|}{ Group } \\
\cline { 2 - 3 } & Cases & Control \\
\hline Normal & 39 & 50 \\
$(5-25 \mathrm{ng} / \mathrm{mL})$ & $78.0 \%$ & $100.0 \%$ \\
\hline Raised & 19 & 0 \\
$(>25 \mathrm{ng} / \mathrm{mL})$ & $22 \%$ & 0 \\
\hline \multicolumn{3}{|c|}{ Table 5. Prolactin } \\
\hline
\end{tabular}

Chi square test Value P. Value Highly Significant. With Yates correction 12.360, 0.000 . 


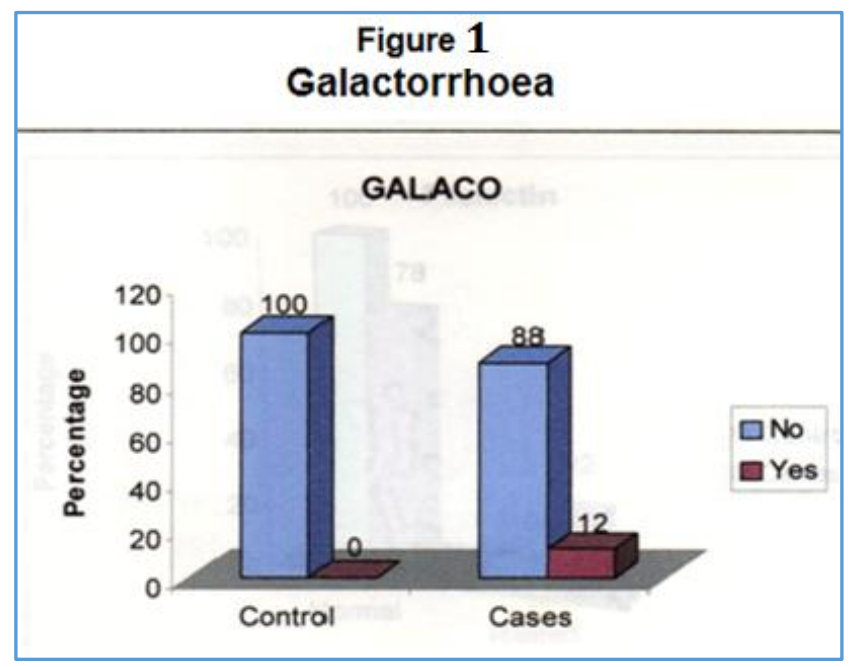

\section{DISCUSSION}

As per Table 1, 38\% of the cases with BMI greater than 25 $\mathrm{kg} / \mathrm{m}^{2}$ are more prone to obesity. Most of the infertile patients are obese. In obesity, there is peripheral conversion of androgen to oestrogen by the enzyme aromatase in the adipose tissue stromal cells. The greater the obesity, the more will be the peripheral aromatisation of androgens to oestrogens especially oestrone. The high concentration of oestrone sensitises the pituitary to secrete excessive androstenedione, which perpetuates the vicious cycle of androgen to oestrone. Anovulation is because of the disturbance in the dynamics of androgen-oestrogen conversion. There is altered feedback regulation of cyclic gonadotropin release because of the constant outpouring of oestrogen from extraovarian sources. (oestrone hypothesis of Asharmasya et al 1999). 6

Oestrogen appears in three forms in circulationoestradiol, oestrone, oestriol. LH surge leading to ovulation can occur only in the presence of excess oestradiol in the serum. Oestrone levels increased due to peripheral conversion of androgens in extraovarian sources. This exerts a negative feedback effect on the secretion of FSH from anterior pituitary. Low FSH level can impair the production of oestradiol in ovary.7 Low FSH levels impair granulosa cell growth and inhibits aromatase enzyme essential for conversion of androgen to oestrogen (Short and London 1961). 8,9 More and more androgens enter the circulation. But there may be decreased concentration of sex hormone binding globulin due to decreased levels of thyroid hormones. So androgens in the circulation remain as free androgens resulting in hirsutism. ${ }^{10}$ This is indicated by the results of analysis as per Figure 1, which shows 38\% cases with hirsutism. This androgen excess is reversible with weight loss.

Regarding the relationship of dysmenorrhoea with infertility, there is a strong supportive correlation as evidenced by the occurrence of dysmenorrhoea in $84 \%$ cases in this study. Dysmenorrhoea is due to uterine smooth muscle contraction induced by increased levels of prostaglandins in menstrual fluid by secretory endometrium. ${ }^{11}$ Dysmenorrhoea is usually associated with ovulatory cycles. The occurrence of dysmenorrhoea is associated with the release of PGF $2 \alpha$ from the endometrium. Synthesis of PGF2 $\alpha$ is dependent on oestrogen and progesterone production which definitely occurs only after ovulation. In anovulatory cycles, ${ }^{12}$ there is increased oestrogen unopposed by progesterone which causes a hyperplastic or proliferative endometrium with a reduced capacity to synthesise PGF2 $\alpha$. This explains the absence of painful menses in $16 \%$ of cases. But there are evidences that prostaglandin is also released from adipose tissue in response to nerve stimulation and catecholamine administration. So dysmenorrhoea may be common in women with high body mass index and infertility. ${ }^{13,14}$

Results of analysis as per Table 4, Figure 2, shows a positive correlation between hyperprolactinaemia, galactorrhoea and infertility. Prolactin synthesis and release from the lactotrophs are controlled by neurotransmitters which act on the pituitary via hypothalamus. The main control mechanism is inhibition by dopamine which acts on the pituitary. Although prolactin releasing factor has not been isolated it is known that thyrotropin releasing factor stimulates prolactin release. ${ }^{14}$

One of the mechanisms by which elevated prolactin levels cause ovulatory dysfunction is by stimulating the production of dopamine in hypothalamus. Dopamine can inhibit GnRH release by norepinephrine secretion. Decreased GnRH leads to a decrease in the pituitary FSH and LH. A decrease in the FSH and LH is the basis of most prolactin based ovulatory problem. ${ }^{15}$

Prolactin can also decrease progesterone production by granulosa cells when grown in culture. This can also lead to luteal phase defect and anovulation. ${ }^{16,17}$

Another mechanism has been put forward for the cause for ovulatory dysfunction associated with raised prolactin levels. Hyperprolactinaemia can cause alteration in $\mathrm{GnRH}$ release not synthesis. ${ }^{18}$ Alteration in GnRH release cause abnormalities in the frequency and amplitude of gonadotropins especially LH pulsations. Alterations in LH pulsations can affect ovulation. Thus, elevated levels of prolactin directly inhibit basal as well as gonadotropin stimulated ovarian secretion of oestrogen and progesterone, which can cause ovulatory dysfunction. ${ }^{19,20}$

In addition, there are prolactin receptors on the adrenal gland. The adrenal glands respond by an increase in their own androgenic hormones which can also interfere with ovulation. ${ }^{21,22}$

In the presence of hyperprolactinaemia, despite adequate releasable $\mathrm{LH}$ and FSH in the pituitary, oestrogen fails to induce a positive feedback release of LH and ovulation will not occur. Suppression of prolactin concentration led to resumption of normal menstrual cycle and ovulation. ${ }^{23}$

The observation in the present study points to the fact that a closely intertwined relationship exists between serum prolactin and infertility. Ideally complete followup of all patients attending the infertility clinic should be done which is not possible during the short span of the study. Hope this study is successful in the explanation of pituitary-ovary relation and add to the practical knowledge of human reproduction. It is our hope that the future workers in this field would be benefitted with more insights into the enigma that serum prolactin continues to alleviate the anguish of the couples concerned and those in the medical profession alike.

\section{CONCLUSION}

The present study supports the possible role of serum prolactin in infertility. In addition, Body Mass index, 
dysmenorrhoea, dyspareunia play a vital role in infertility. So, appropriate screening of all infertile patients is recommended, routinely to evaluate pituitary function by prolactin estimation. Associated obesity, hirsutism, dysmenorrhoea, dyspareunia should be investigated. The screening and treatment of these patients should be continued even after conception. This might help in the early initiation of corrective measures that prevent or limit the damage to mother and foetus. Hope this study may throw light for all the couples concerned who seek treatment for infertility.

\section{Limitations of the Study}

The study was of short duration. Proper followup of the patients was not done.

\section{REFERENCES}

[1] Kamilova DP. Infertility in women with galactorrhea. Akush Ginekol (Mosk) 1993;6:52-4.

[2] Grubb MR, Chakares D, Malarkey WB. Patients with primary hypothyroidism presenting as prolactinomas. Am J Med 1987;83(4):765-9.

[3] Newmark SR, Rossinii AA, Naftolin FI, et al. Gonadotropin profiles in fed and fasted obese women. Am J Obstet Gynecol 1979;133(1):75-80.

[4] Kapcala LP. Galactorrhea and thyrotoxicosis. Arch Intern Medicine 1984;144(12):2349-50.

[5] Baird DT. Endocrinology of female infertility. Br Med Bull 1979;35(2):193-8.

[6] MnNeilly AS. Effect of lactation on fertility. British Medical Bulletin 1979;35(2):151-4.

[7] Edwards CRW, Forsyth IA, Besser GM. Amenorrhoea, galactorrhoea, and primary hypothyroidism with high circulating levels of prolactin. $\mathrm{Br}$ Med J 1971;3(5772):462-4.

[8] Baird DT, Fraser IS. Disorders of hypothalamicpituitary-ovarian axis. Clin Endocrinol Metab 1973;2(3):469-88.

[9] Speroff L. The effect of aging on fertility. Curr opin obstet gynecology 1994;6(2):115-20.

[10] Raber W, Gessl A, Nowotny P, et al. Hyperprolactinaemia in hypothyroidism: clinical significance and impact of TSH normalization. Clin Endocrinol (Oxf) 2003;58(2):185-91.
[11] Kalro BN. Impaired fertility caused by endocrine dysfunction in women. Endocrinol metab clini North Am 2003;32(3):573-92.

[12] Glass AR, Dahms WT, Abraham G, et al. Secondary amenorrhoea in obesity: etiologic role of weightrelated androgen excess. Fertil steril 1978;30(2):2434.

[13] Muse K, Wilson EA, Jawad MJ. Prolactin hyperstimulation in response to thyrotropin-releasing hormone in patients with endometriosis. Fertil steril 1982;38(4):419-22.

[14] Green BB, Weiss NS, Dailing JR. Risk of ovulatory infertility in relation to body weight. Fertil steril 1988;50(5):721-6.

[15] Shushan A, Eisenberg VH, Schenker JG. Subfertility in the era of assisted reproduction: changes and consequences. Fertil Stent 1995;64(3):459-69.

[16] Georgopoulos NA, Markou KB, Pappas AP, et al. Ovulation induction with pulsatile gonadotropinreleasing hormone $(\mathrm{GnRH})$ or gonadotropins in a case of hypothalamic amenorrhea and diabetes insipidus. Gynecol endocrinol 2001;15(6):421-5.

[17] Isaksson R, Tiitinen A. Present concept of unexplained infertility. Gynecol endocraniol 2004;18(5):278-90.

[18] Collins JA. Physiopathological determinants of human infertility. Human Reproduction update 2002;8(3):435-47.

[19] Shalev E, Eliyahu S, Ziv M, et al. Routine thyroid function tests in infertile women: are they necessary? Am J obstet gynecol 1994;171(5):1191-2.

[20] Crosignani PG, Rubin BL. Optimal use of infertility diagnostic tests and treatments. The ESHRE capri workshop group. Human Reproduction 2000;15(3):723-32.

[21] Vaidya R, Shringi M. Thyroid and female reproduction. Journal of Post graduate Medicine 1993;39(3):118-9.

[22] Bhandarkar SD, Chadha M, Balaiah D, et al. Menstrual irregularities and lactation failure may precede thyroid dysfunction or goitre. Journal of Post graduate Medicine 1993;39(3):137-41.

[23] Baird DT, Corker CS, Davidson DW, et al. Pituitaryovarian relationships in polycystic ovary syndrome. Journal of clinical Endocrinol metab 1977;45(4):798801. 